\title{
Energy, Society and Morals ${ }^{1}$
}

\author{
GÖRAN WALL \\ Solhemsgatan 46, SE-431 44 Mölndal, Sweden \\ Tel./Fax: +46-31-877579; Email: gw@exergy.se; WWW: http://exergy.se/
}

\begin{abstract}
The present trend of resource depletion and environmental destruction relates to a lack of morals in society. Available tools like exergy, ecology and democracy are ignored. This makes us unaware of reality and also of possibilities to avoid a catastrophe. Instead, economics and politics are often based on myths. The most dangerous threat to mankind is new, unknown diseases, nourished by the environmental pollution. Also this knowledge is suppressed. The conclusion is that too much attention has been given to the body of the society, i.e. its metabolism. Therefore more concern must be put into the soul of the society, especially morals and love.
\end{abstract}

\section{Introduction}

This paper origins from earlier work. $\{1\}$ Exergy, ecology and democracy are important tools in a vital society. $\{2\}$ Exergy relates to the physical world, ecology describes the living nature and democracy is the best tool for human co-operation. ${ }^{2}$ In order to improve systems involving all these parts, i. e. a society, all of these tools must be considered, and an exergy tax has been proposed as an active force to introduce into present economics. \{2\} However, the driving forces in a vital society must be based on morals and love. Morals can and should be studied, learned and practiced, but love is a noun and can only be experienced by itself. However, it must be regarded and respected as well as supported by the society.

Nothing disappears and everything disperse, these are two fundamental laws referring to the first and second laws of thermodynamics. These laws have a strong impact on our living conditions. The resource use in the developed world implies a resource depletion and an environmental destruction never seen before in the history of mankind. Resource management is characterized by unconscious incompetents, mainly based on a number of myths and lack of morals. $\{2\}$

At present process of change man is facing a soon extinction. The first signs are already visible; new diseases appear in many developed countries. The situation can be described by Figure 1. The environmental pollution changes the chemical composition of the environment, i.e. the reference state. This causes the nature to create new forms of life and organisms, as it has always done. Some microorganisms may create 25,000 new generations in a year, so new organisms quickly appear. Sometimes we see this as a sudden and mysterious numerous death among animals and plants from poisonous algae or viruses or as an increased human mortality from cancer and allergy. In short, the present industrial development is nourishing new diseases that will kill all higher forms of life, just as the Black Death, spread by a flee on the black rat, ones killed millions of people in the 14th century. This is how nature works. The natural evolution will continue and the nature will remain long after man and other species are gone. Of course, man will extinct anyhow, but not so soon.

Thus, the situation is clear. One may argue about details, such as how or when, but not that a culture based on resource depletion and environmental destruction is doomed. So, why is nothing done? Present science is mainly busy measuring how the catastrophe proceeds or busy defending present engineering. It also lacks perspective, scientists work inside "tubes", without connection to other "tubes". The outside world is often regarded as non-science or of no interest. Pirsig $\{3\}$ calls it a "cultural immune system ... First you say things our way and then we'll listen to you". The scientific society is somehow also caught in a situation of continuous apply for funding - survival - from governmental or industrial establishments. A paramount consideration for most scientists is funding, just as reelection is for most politicians. The

\footnotetext{
${ }^{1}$ A modified version was published in JOURNAL OF HUMAN VALUES 3:2 (1997) Sage Publications New Delhi/Thousand Oaks/London, pp. 193-206

${ }^{2}$ Nota bene, I am here referring to direct democracy, i.e. true democracy and not oligarchy.
} 
situation is also dangerous for science itself because science is ruled by non science. Science becomes valued by the size of the budget and managed by loyal "dollar scientists". What government or institutional establishment will support critics? Very few, I am afraid. The situation inevitably brings prostitution to mind. Neither Darwin nor Einstein would have been funded by the present system. This is our problem. Few consider the reality. Morals are banned by science, "morals have been declared intellectually illegal" $\{3\}$ and lost in politics. The recent experiment by Sokal shows that the scientific society is also partly corrupted. A leading journal of cultural studies, Social Text, publishes bullshit if (a) it sounds good (b) it flatters the editors' ideological preconceptions. \{4\} Thus, morals are also lost in science. All this creates an excellent environment for myths to flourish in society.
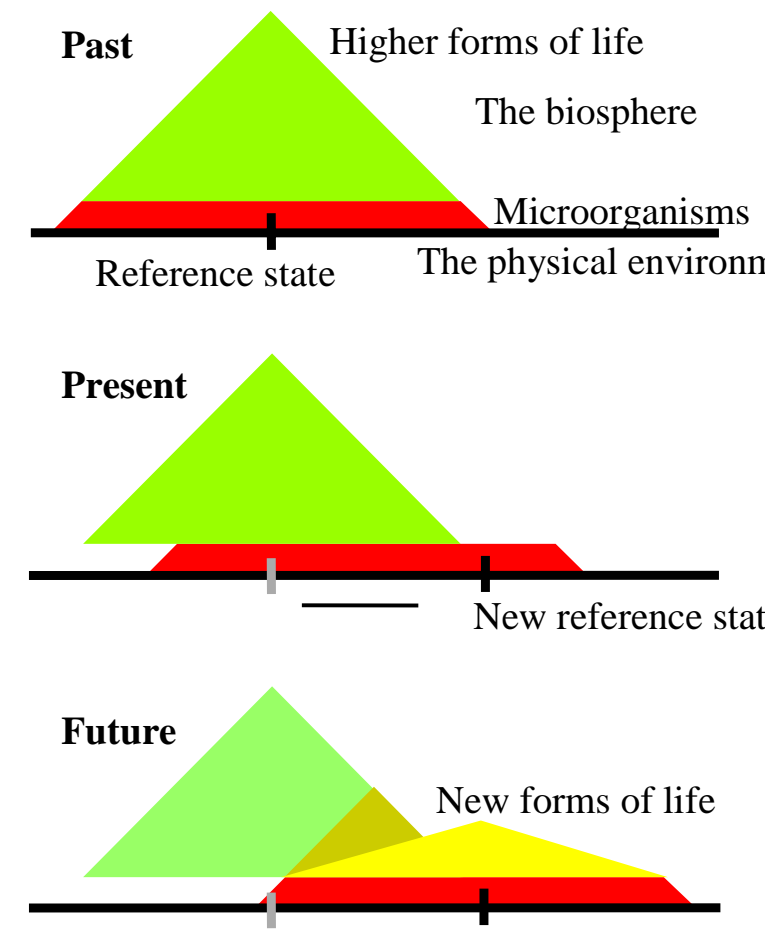

Figure 1. "The Survival of the Fittest"

Our cultural myths hinder awareness, we are captives of "Mother Culture”. \{5\} Myths give a wrong picture of the reality which makes it hard to understand and improve real systems, the energy system is just but one example.

In 1975 Alfvén \{6\} compared the energy accounting based on first law of thermodynamics, with a cashier counting cash only by the number of coins or notes, and neglecting their value. Energy planning is still based on first law accounting and limited to only pure energy resources, see Figure 2. $\{7\}$ The diagram is more than 20 years old, but still represents present energy planning in the developed world. What would happen if a bank practiced "first law" accounting? I am sure it would be brought into court. However, when it concerns reality no one seems to care. The conclusion is that in our culture sometimes fiction based on myths is more important than truth. This also gives a reasonable explanation to why the present Western culture will end in a catastrophe, since it simply ignores basic tools of physics to establish and maintain vitality.

By using the concept of exergy or the second law of thermodynamics, stated in the year 1824 by Carnot $\{8\}$ the picture of Figure 2 will change dramatically, see Figure 5 below. \{7\} However, let us first look closer to the concept of exergy and the second law of thermodynamics. 


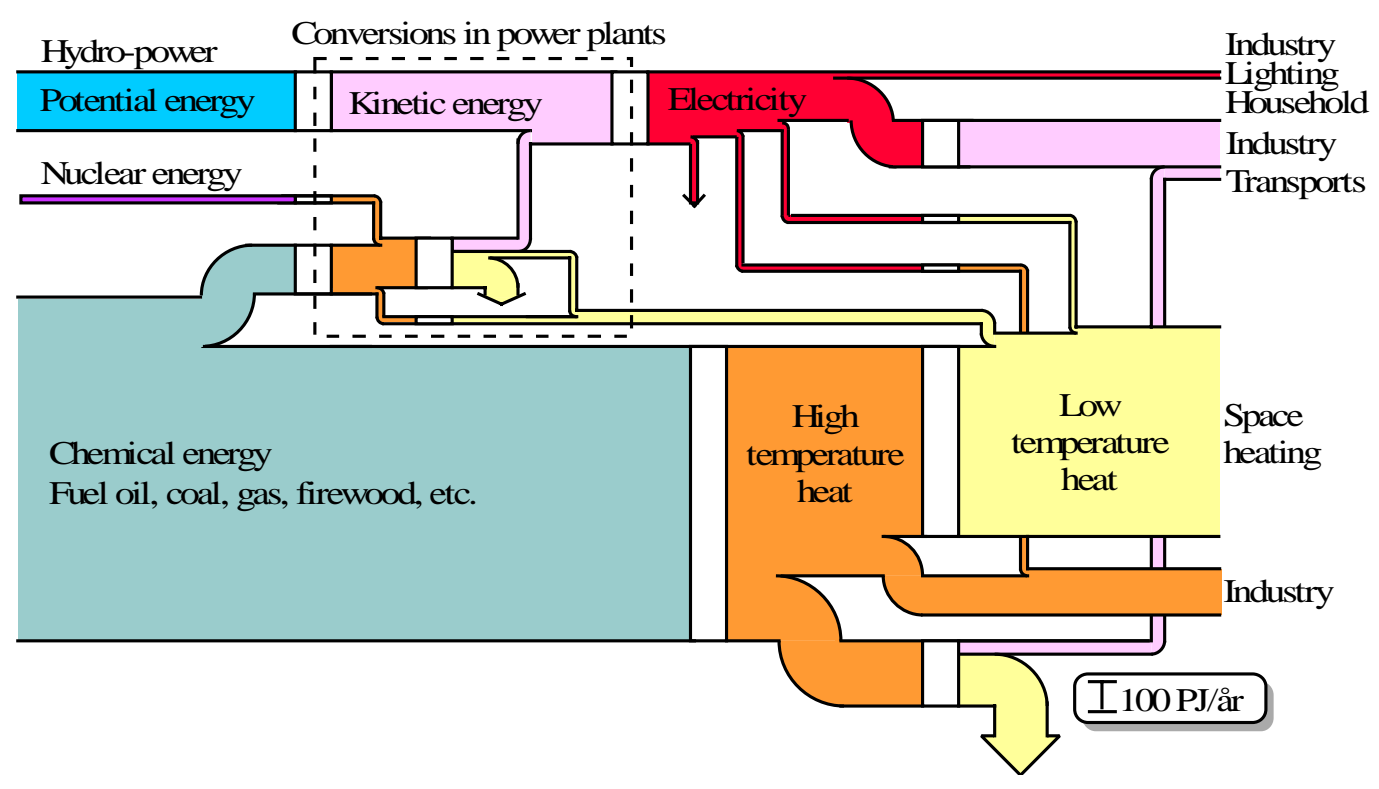

Figure 2. The energy conversion system in Swedish society 1971 in energy units.

\section{Energy, Exergy and Society}

Energy and exergy could be expressed: (1) energy is motion or ability to produce motion and (2) exergy is work (= ordered motion) or ability to produce work. Motion is often work without a specific direction, i.e. work without meaning. Thus, energy is most often an all too hazy concept, whereas exergy is more strict.

The exergy $E$ of a system in a large environment ${ }^{3}$ is $\{7\}$

$$
E=T_{0}\left(S_{\text {eq }}^{\text {tot }}-S^{\text {tot }}\right)
$$

where $T_{0}$ is the temperature of the environment and $S_{\text {eq }}^{\text {tot }}-S^{\text {tot }}$ is the deviation from equilibrium of the negentropy (=minus the entropy) of the system and its environment, i.e. the total system. ('eq' denotes equilibrium with the environment.) The exergy may also be written as $\{9\}$

$$
E=S\left(T-T_{0}\right)-V\left(p-p_{0}\right)+\sum_{i} n_{i}\left(\mu_{i}-\mu_{i 0}\right)
$$

where the extensive parameters are entropy $S$, volume $V$ and number of moles of substance $i n_{i}$, and the intensive parameters are temperature $T$, pressure $p$, and chemical potential of substance $i$ $\mu_{i}$ for the system, the subscript 0 relates to the reference environment. $\{10\}$ We see that exergy approaches zero as the system approaches equilibrium. Effects of electricity, magnetism, gravity, radiation, etc. can also be added.

Analogously, the exergy of a flow, i.e. open system, becomes

$$
E=U-U_{\text {eq }}+p_{0}\left(V-V_{\text {eq }}\right)-T_{0}\left(S-S_{\text {eq }}\right)-\sum_{i} \mu_{i 0}\left(n_{i}-n_{i, \text { eq }}\right)
$$

where $U$ is the internal energy and on the right side easily determined quantities appear. $\{11\}$ It is thus an easy task to determine the exergy content of a given system in a given environment. To conclude this introduction we may state that the first and second law of thermodynamics says that energy is always conserved and exergy is always consumed.

\footnotetext{
${ }^{3}$ Exergy may also be related to any given state, but then it has no relation to the environment.
} 
Natural resources are traditionally divided into energy and other resources. This separation is often only arbitrary, e.g. oil, is usually regarded as energy and wood as a construction material. However, oil can also be used for producing useful materials and wood can be used as a fuel. It would be more appropriate to consider these resources together and to use exergy as a resource measure. The exergy content of energy resources may be given by their energy content multiplied by an exergy factor, see Table 1 .

Table 1. The exergy factor of some common energy forms.

\begin{tabular}{|l|c|}
\hline Energy form & Exergy factor \\
\hline Mechanical energy & 1.0 \\
Electrical energy & 1.0 \\
Chemical energy & about $1.0 \dagger$ \\
Nuclear energy & 0.95 \\
Sunlight & 0.93 \\
Hot steam $\left(600^{\circ} \mathrm{C}\right)$ & 0.6 \\
District heat $\left(90^{\circ} \mathrm{C}\right)$ & $0.2-0.3 \ddagger$ \\
Heat at room temperature $\left(20^{\circ} \mathrm{C}\right)$ & $0-0.2 \ddagger$ \\
Thermal radiation from earth & 0 \\
\hline
\end{tabular}

$\lceil$ May exceed 1, due to definition of system boundaries and final states $\ddagger$ Depend strongly on the outdoor temperature

Similarly, materials can be quantified in exergy, e.g. by an exergy factor of unit $\mathrm{J} / \mathrm{m}^{3} \mathrm{or} \mathrm{J} / \mathrm{kg}$. This could be the start of an expanded resource budgeting and a first step towards an integration with traditional energy accounting. Exergy is the physical value of a resource that can be compared to the economical value.

The exergy concept is mostly used within studies, where different energy forms occur. $\{12\}$ However, the field of application can be extended to the total societal metabolism. This yields a uniform description of the use of physical resources and the environmental impacts from this use.

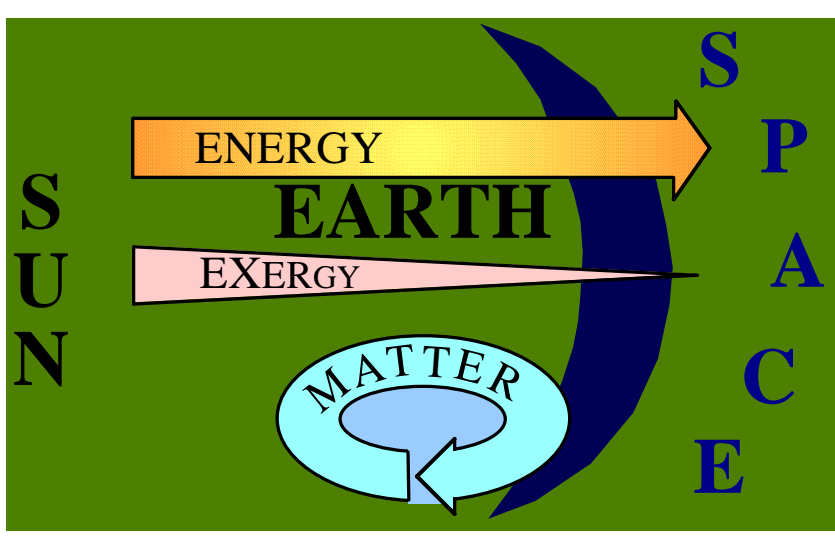

Figure 3. Flows of energy and matter on earth are driven by exergy, i.e. the contrast between the sun and space.

Exergy from the contrast between the sun and space drives flows of energy and matter on the surface of the earth, see Figure 3. $\{13\}$ When exergy reaches the earth, it is gradually destroyed, but on the way it manages to drive, among other things, the water/wind system, and life on earth. Complex structures, rich in exergy and capable of reproduction, are formed by photosynthesis in the biosphere.

In Figure 4, we see how the exergy flow through human society is maintained. The greater part of the exergy requirements are seen to from the terrestrial exergy stocks. Man only uses a very small part of the direct exergy flow from the sun, mainly within agriculture. In society there is, on the whole, a continuous exergy loss. Some exergy flows, such as flows of metals from 
ores, increase their exergy when passing through society. However, other flows decrease their exergy all the more, just as is stated by the second law of thermodynamics given above.

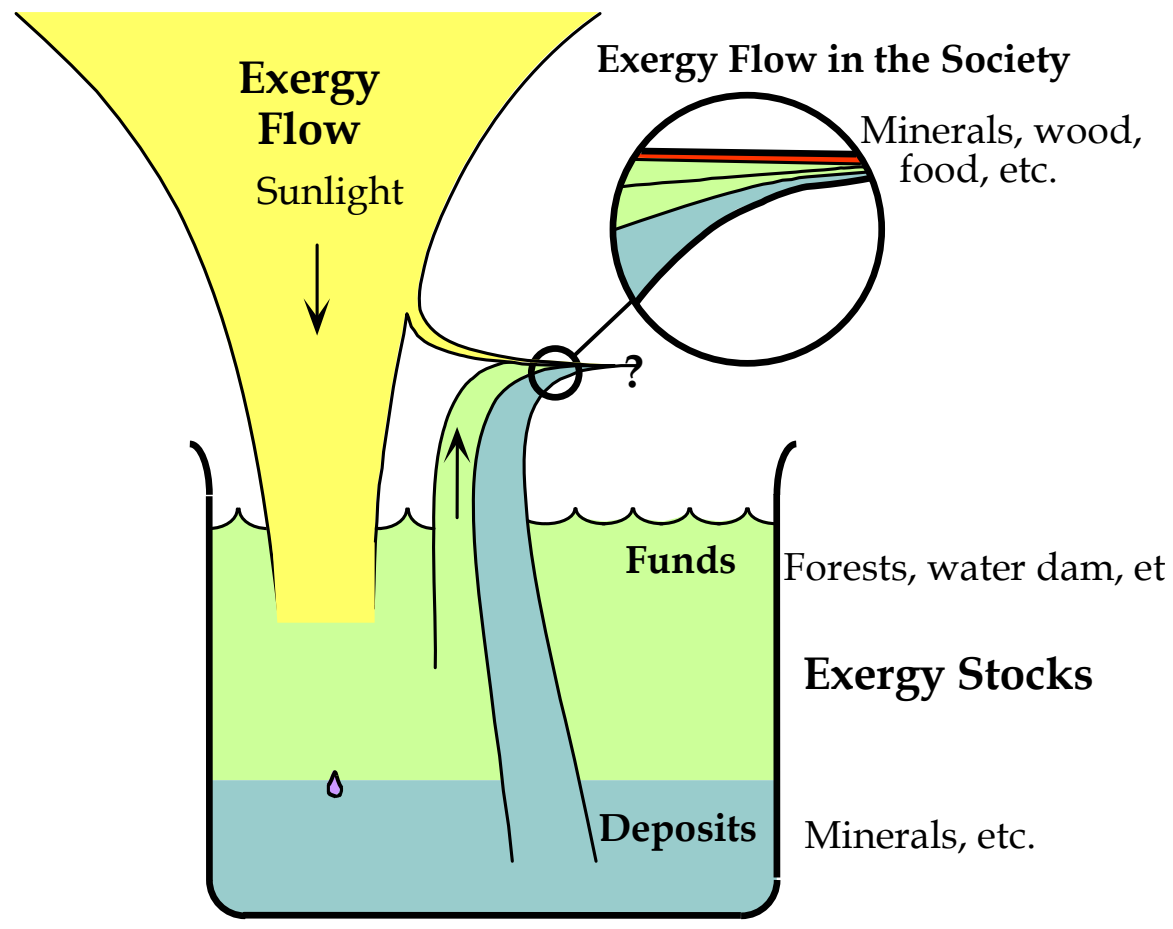

Figure 4. The exergy flow from the sun, and the exergy stocks on earth create the resource base for human societies on earth.

Applying exergy gives a completely different picture of the energy system in Figure 2 above, see Figure 5. This picture also gives a reasonable explanation to why the energy establishment so vigorously avoid the use of the exergy concept. The miserable energy situation becomes too obvious. Energy is a perfect concept to cover up the real losses in the energy system. However, this raise a question of loyalty or morality, maybe in rare cases also competence. Are the energy establishment loyal to the truth and the people it is supposed to serve or what? If legal, still it is an obvious case of morality. Our culture's tendency to cover up the truth is ruining its vitality.

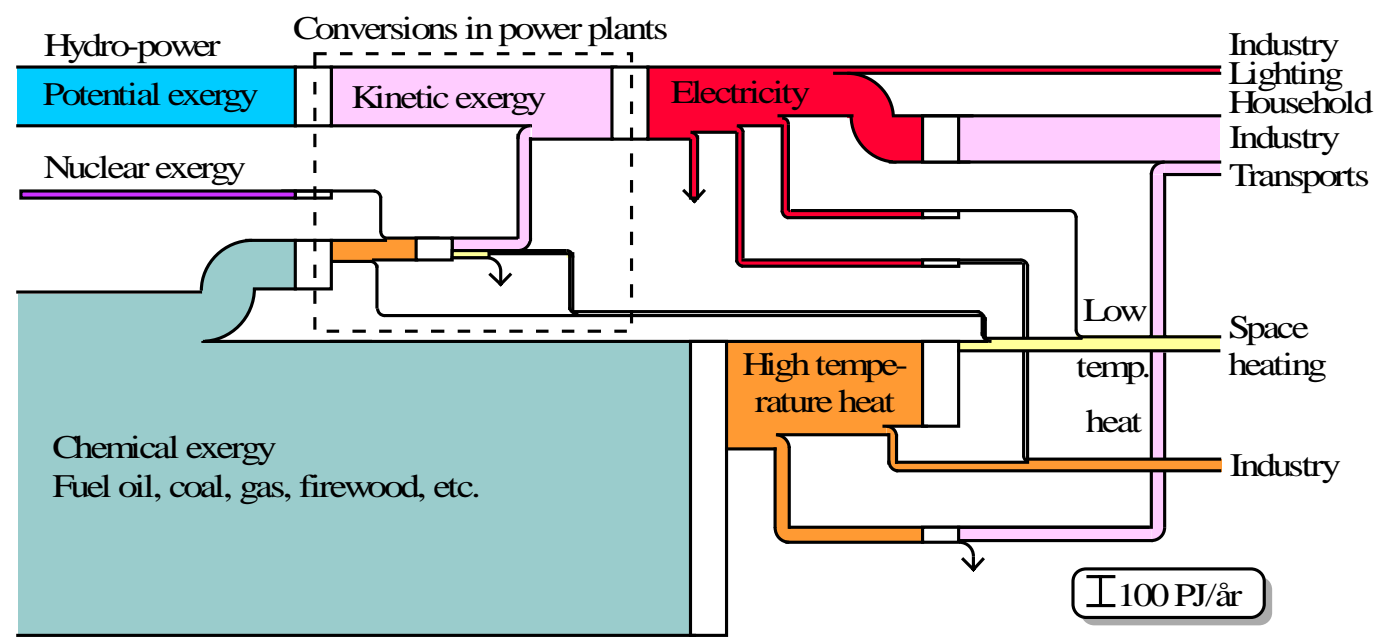

Figure 5. The energy conversion system in Swedish society 1971 in exergy units.

If we also include other physical resources than energy we may get the picture in Figure 6, which refers to Italy in 1990. $\{14\}$ 


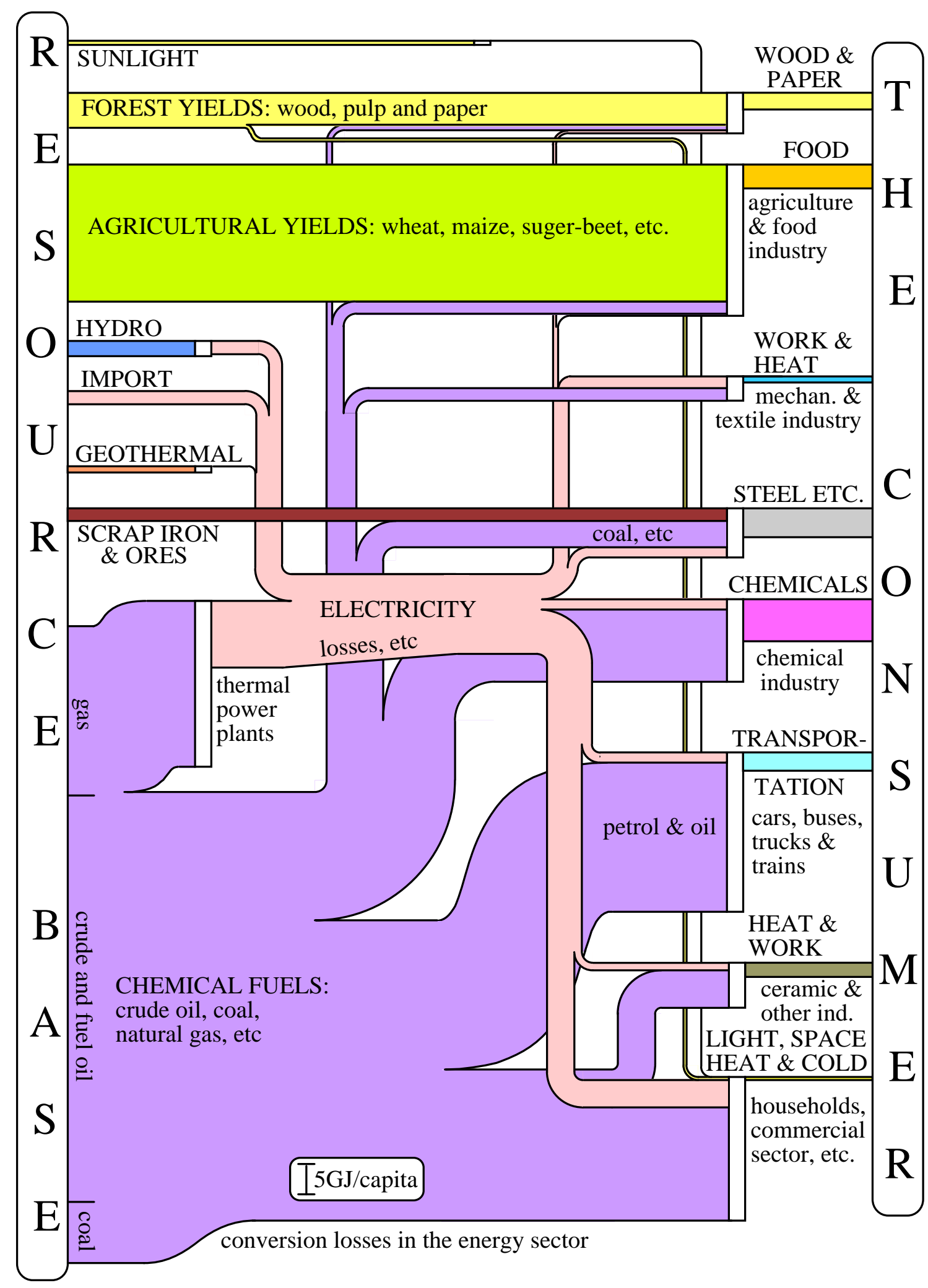

Figure 6. The exergy-conversion system in the Italian society in 1990. The total input was about 8300 PJ (of which about 6500 are energy related) or $140 \mathrm{GJ} /$ capita and the net output $1500 \mathrm{PJ}$ or $25 \mathrm{GJ} /$ capita

The physical resources in Figure 6 are classified in natural flows like sunlight, funds such as forest and agricultural yields and hydro, and deposits. In a vital society, the use of physical resources must depend almost entirely from renewable resources, i.e. natural flows and funds. 
From Figure 6 we see that this is not the case, which is the case for most developed countries. Let us regard the situation in a developing country, Ghana 1975, see Figure 7. \{15\}

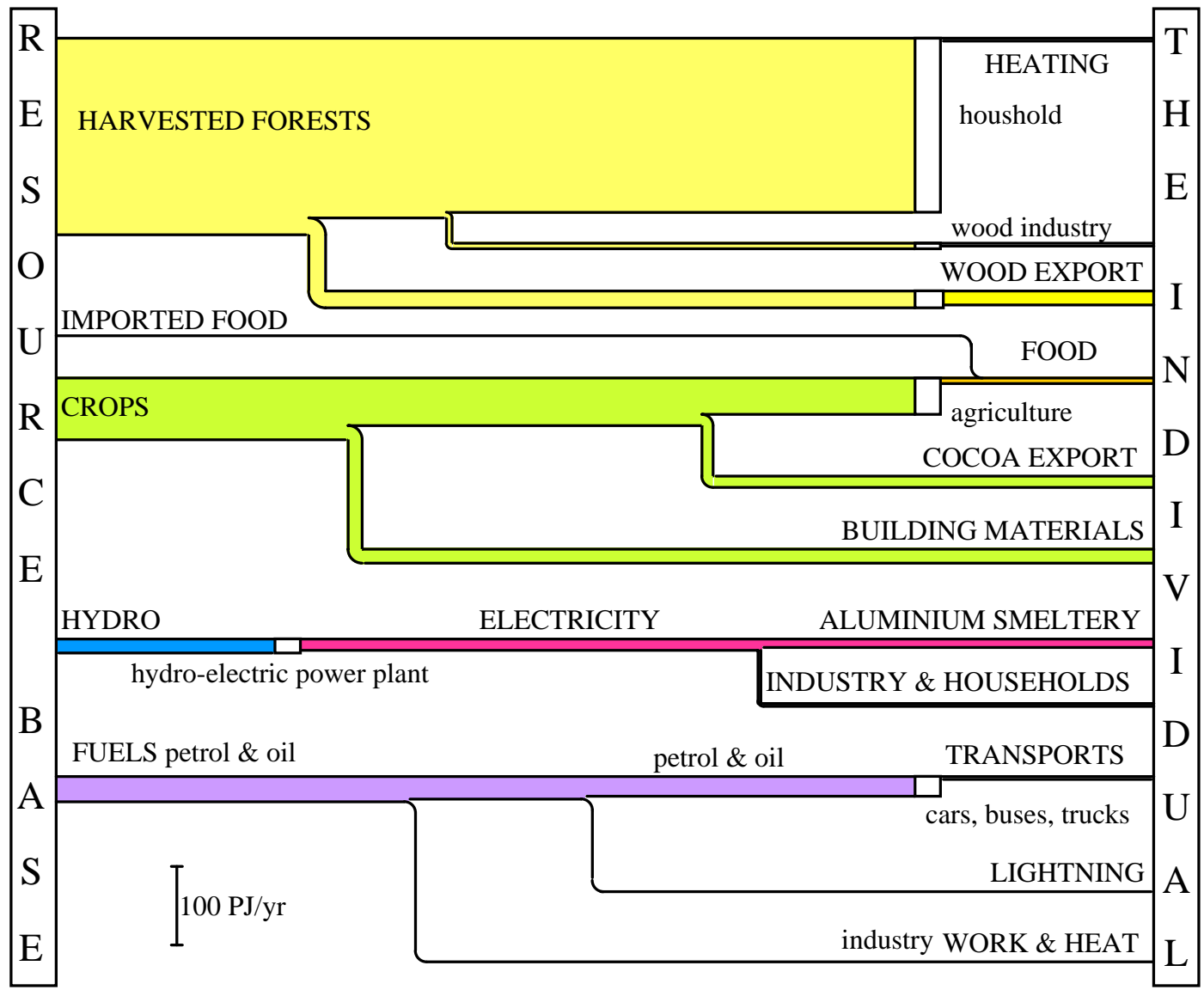

Figure 7. The exergy conversion system in the society of Ghana in 1975 . The total input was about 400 PJ or 40 GJ/capita and the net output $110 \mathrm{PJ}$ or $11 \mathrm{GJ} /$ capita

Usually the physical resource use in developing countries to a greater extent origins from renewable resources. From, this point of view they are obviously more vital than developed countries. Usually the level of resource use differs by magnitudes between developing and developed countries. However, from Figure 7 we also see a lack of infrastructure, also typical for developing countries. We can see that they are part of an external system, referred to as neocolonialism. Every attempt to develop is stopped by the "invisible foot", usually a corrupt leadership linked to organized development assistance. \{16\} However, our false picture sometimes makes even common friendship act as the "invisible foot". Cloth-raising drives in the developed world ruins every attempt to build a local cloth industry in the developing world. The "invisible foot" need to be made public.

From Figs. 5, 6 and 7 we can see heavy losses in some sectors, especially the space heating system. Sometimes the utilization is less than $0.25 \%$, see Figure 8 . \{2\} From a physical approach this is a disaster, but still economically and politically justified. In this case the pervious question of loyalty or moral of the energy establishment becomes even more justified. Especially if we also consider the true risk of nuclear disasters like Harrisburg in 1979 and Chernobyl in 1986. In this case reality is covered up by making it not probable and excluding normal human behavior.

Of the total inflow of physical resources into industrialized societies often less then $20 \%$ reaches final use. $\{14,17,18\}$ Heavy losses could be considerably reduced by an active resource budgeting and economizing at all levels in the society. In particular, better insulation would decrease the need of space heating and air-conditioning, and would also improve indoor comfort. Traditional housing sometimes offers a better alternative then modern western buildings. 
Exergy is the fuel for all systems, converting energy and matter, e.g. a living cell, an ecosystem, or a human society. Thus, exergy studies provide us with knowledge of how effective and balanced a society is regarding physical resource use. This information can be used to identify areas where technical and other improvements could be undertaken, and indicate the priorities that could be assigned to conservation measures. The exergy concept must, therefore, be used systematically to describe such systems scientifically. Or, as recently stated by Goodstein "In a world rapidly running out of fossil fuel, the second law of thermodynamics may well turn out to be the central scientific truth of the twenty-first century." $\{19\}$ Resource depletion and environmental destruction are mainly consequences of a poor management. Exergy analysis offers a more competent management and also a first step towards a more Nature-Oriented Technology. $\{20\}$ Making comparisons of this type between various societies throughout the world and studying the international system should also be of fundamental interest if we are serious in our efforts to work towards a more equitable, i.e. a morally more justified, distribution of resources in the world.

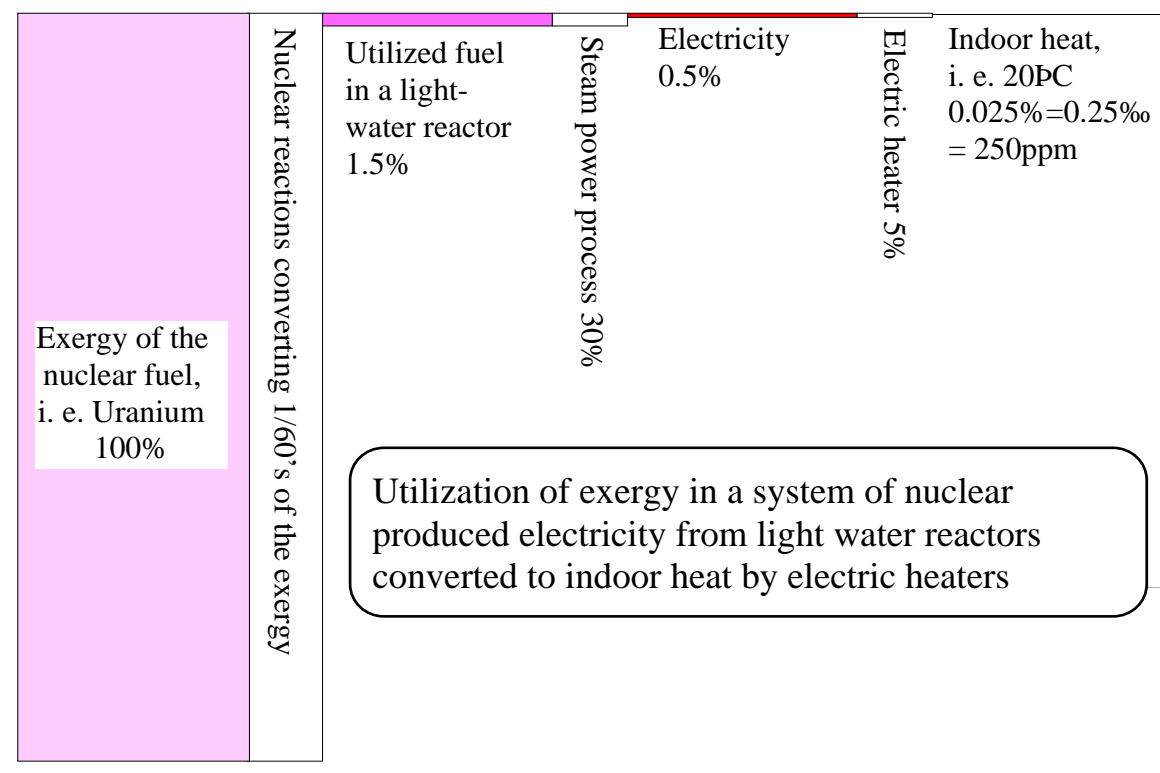

Figure 8. Nuclear fuel in Light Water Reactors for space heating by short circuiting.

\section{Myths and Morals}

Thus, the present situation raises the question of morals. Engineering justified by economic and politic believes, i. e. myths, is a propelling force to extinct life. Big projects are run as if people did not exist or at least were not able to think or act themselves. $\{21,22\}$ It is time to stop and think.

From ecological point of view, the present resource use in the society is a dead end technology, Figure 9, creating nothing but dead in the long run. Deposits are exploited, used and become waste in a one-way flow. Instead we need to develop a vital engineering, similar to what is practiced by nature, see Figure 10. \{2\} From Figs. 9 and 10 it is also obvious that our culture works against the previous natural evolution.

The nature's engineering has so far generated ability of self reproduction, i.e. life, and ability of awareness practiced by higher forms of organism of which man is only but one example. We call this natural evolution, and it was first described by Darwin in the work "On the origin of species by means of natural selection" in 1859. Present societal evolution is increased Gross National Product (G.N.P.). This is when rain forests are replaced by asphalt, concrete, smokestacks and electric cables, or when rice fields being farmed for 5000 years convert to golf greens. 
Also concepts like truth and democracy have lost their true meaning in our society. $\{23,24\}$ The care for the young generation is mainly left to commercial interests, and their messages differ completely from that of most parents, see Table 2. \{25\} In short the messages are Act! versus Think! Obviously, the society lacks a sense of morality towards the rising generation.

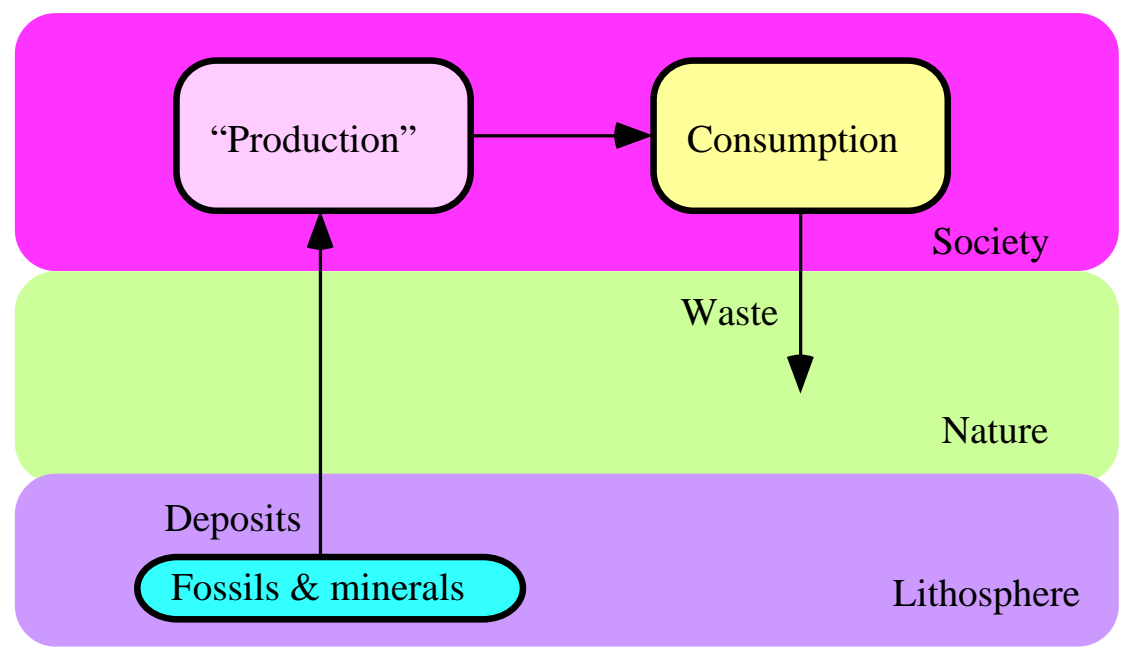

Figure 9. The society takes deposits from nature and returns wastes.

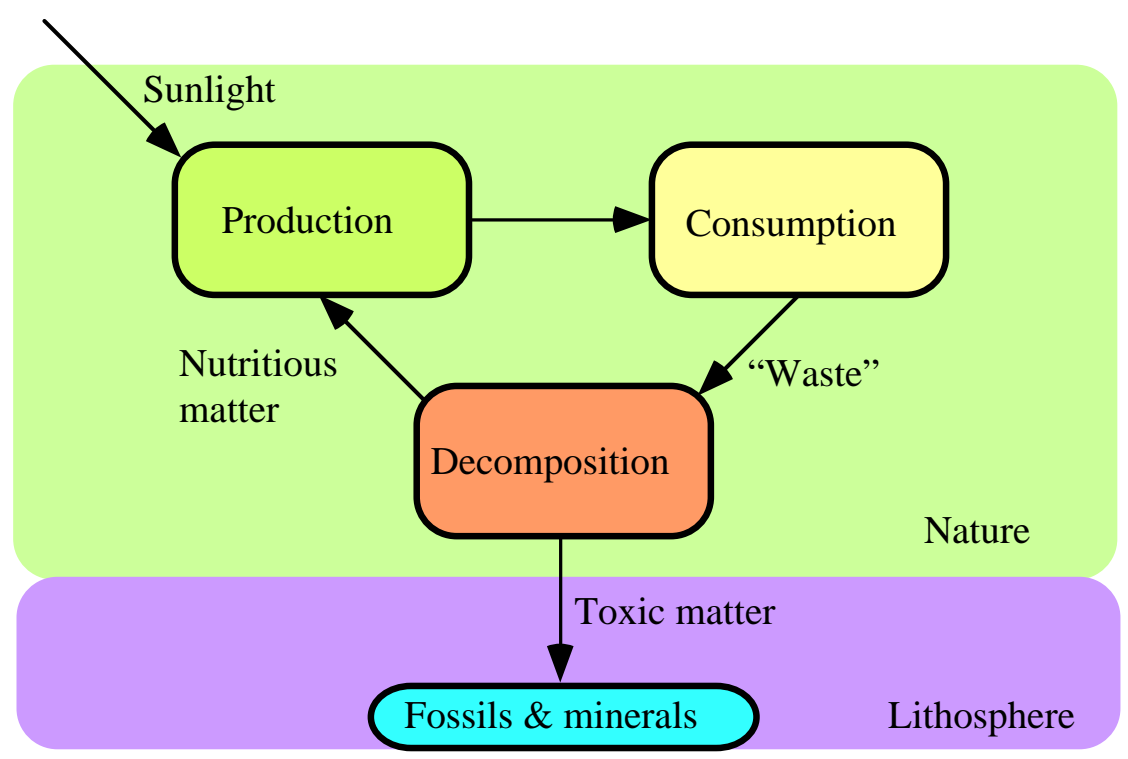

Figure 10. The natural evolution is forced by sunlight and is "self cleaning".

International conferences on poverty and famine or environmental protection offer no hope as long as the conclusion is continuous economic growth for the developed world. $\{26,27\}$ We must also remember that politicians and leaders have always put forward the most "important" issues of the time to justify themselves. This is what makes them to leaders in non democratic ${ }^{4}$ societies.

Since the works of Lao Tzu and Plato very little has been added to the question of morals in the society. I do not consider philosophological ${ }^{5}$ discussions of the concept of morals. Pirsig is one of the few present philosophers stressing the subject. $\{3\}$ These ancient texts should be

\footnotetext{
${ }^{4}$ With democracy I mean true democracy, i.e. not monarchy or oligarchy which today is often falsely named democracy.

${ }^{5}$ The study of philosophers.
} 
studied in school, to establish a growing awareness of morals in the society. At least it might be a first step to become aware of ourselves.

Table. 2 The messages to the young generation from most parents and from the commercial sector.

\begin{tabular}{|c|c|}
\hline What most parents wish & The commercial message \\
\hline Care, understanding and respect & Ruthless, violent and selfish \\
\hline Honest & Smart \\
\hline Generous and pleasant & Demanding and self-centered \\
\hline Deep roots & Rootless \\
\hline Interest-free economy & High interest \\
\hline Plan far ahead & Live for the moment \\
\hline Interest in nature & Worship Metropolis and MTV \\
\hline Pleasure peacefulness & Action and high jinks \\
\hline Nature conveys security & Nature scares \\
\hline Thoughtful and careful & Ventures and "Dare — win!“ \\
\hline Look for true values & Look for action and easy money \\
\hline Give love & Demand sex \\
\hline Be yourself & Pose, be artificial, and fashionable \\
\hline Skeptical against motorism & Worship motorism \\
\hline Do yourself, save and repair & Consume, throwaway and buy new \\
\hline Regard yourself as a part of all & Regard yourself the be-all \\
\hline Avoid tobacco, liquor and drugs & Use tobacco, liquor and drugs \\
\hline The children before the career & Your career before the children \\
\hline
\end{tabular}

\section{Conclusions}

The present situation of resource depletion and environmental destruction can only be changed by finding its causes. Therefore, we must ask ourselves: Why has our civilization ended up in this situation? Where did it all went wrong? What can we do to avoid a catastrophe? Is it just a matter of better measuring, collecting more data and keeping better records? My answer is that the reason to society's failure is to find in its roots, i.e. in its lack of a spirit and a soul. Just as human beings need both body and soul to be vital, so do societies. For a long time most concerns and efforts have been put into building the body of the society, i.e. the metabolism. The agricultural revolution turned us into farmers, useful bricks in the building of empires. Human beings were taught to fight each other, as well as nature. Through religions natural believes and behavior could be oppressed. The industrial revolution brought us even further away from nature and natural behavior. The fight now became global and also moved to future generations by resource depletion and environmental destruction. All this is justified through a huge administration of propaganda, involving almost the entire intelligentsia and capital of the society; the war business being probably the most obvious sign of social corruptness. Gradually, the soul of the society is reduced to greed, competition and entertainment, e.g. business, drugs, sports, news and education. A sick soul in a healthy body will never work and it will also make the body sick. This is what has happened with the human society. Still, the society's body attracts almost all attention and the soul is forgotten. The cure, according to the propaganda machine, is environmental friendliness in engineering and economy, i.e. a purely pragmatic approach. Hardly any attention is raised to ask how we reached this situation. What are the driving forces? Instead, the same believes which brought us here is assumed to bring us out of this. Of course, this will not work. It will only bring us further down the drain. Instead, we must become aware of ourselves, our believes and behavior. This awareness includes a true picture of ourselves, as indicated above by applying exergy to the resource use in the society. It also includes a true perspective of ourselves, as shown above by applying simple ecology to the flows of energy and matter in nature and society. Finally, it also includes true equality between 
ourselves, based on true democracy. However, these are only the necessary tools to maintain a healthy body. Besides, we need to discover the soul of the society, which must be based on morals and love.

Morals and love have no value at the stock-market and they do not represent typical male attributes, but money and power do. Manliness, not femininity characterizes social values and believes. This is the problem, and not whether leaders are men or women. We must find the roots to our behavior, which will not be an easy task. Morals, treated in philosophy for more than 2000 years, should be an obligatory part of all education. Mainly as a complement to other more pragmatic subjects as science, economics, politics and religion in order to avoid creation of myths. Our educational system must teach us understanding and respect for people and nature, i.e. better attitudes. Thus, human ecology as well as ecology should also be part of all education, especially for engineers. We also need a better perspective of ourselves and our civilization. $\{28\}$ I often ask Europeans if they know why Hong Kong belongs to Great Britain. Very few know. In this paper I have only pointed out some examples where it is easy to start the necessary process of questioning our own believes and myths. By starting this process I hope that we will also be able to re-establish morals and love in society.

Acknowledgment-I wish to thank Dr. Darwish M. K. Al Gobaisi, International Centre for Water and Energy Systems in Abu Dhabi, U. A. E. who made this work possible.

\section{Notes and References}

1. G. Wall, "Exergy and Morals," position paper at "Second-Law Analysis of Energy Systems: Towards the 21st Century,” July 5-7, 1995, Rome, Italy, publ. E. Sciubba \& M. J. Moran, eds. Roma, pp. 21-29.

2. G. Wall, "Exergy, Ecology and Democracy - Concepts of a Vital Society", presented at “ENSEC’93 International Conferens on Energy Systems and Ecology,” 5-9 July, 1993, Cracow, Poland, publ. in Szargut, J., et al., eds., pp. 111-121, 1993.

3. R. Pirsig, Lila-An inquire into Morals, New York, 1991.

4. A. Sokal, "Transgressing the Boundaries: Towards a Transformative Hermeneutics of Quantum Gravity,” Social Text, Spring-Summer, nos. 46-47, 1996.

5. D. Quinn, Ishmael, Bantam, 1992.

6. H. Alfvén, "Exergy report may create a new energy policy" (In Swedish) Svenska Dagbladet, 18 November, 1975.

7. G. Wall, "Exergy - a useful concept within resource accounting," Report no. 77-42, Institute of Theoretical Physics, Göteborg, Sweden, 1977.

8. N. L. S. Carnot, Réflections sur la puisance motrice du feu et sur les machines propres a développer cette puissance, Bachelier, Paris (1824); Fox, R. (ed.), Libraire Philosophique J. Vrin, Paris, 1978.

9. J. W. Gibbs, "A Method of Geometrical Representation of the thermodynamic properties of substances by means of surface.” Trans. Conn. Acad. vol. II, 382-404, 1873 or The Collected Works, Yale University Press, vol. 1, 1928.

10. J. Szargut, D. R. Morris, and F. R. Steward, Exergy Analysis of Thermal, Chemical, and Metallurgical Processes, Springer, 1988.

11. S. M. Berman, et al., eds., Efficient Use of Energy, American Institute of Physics Conference Proceedings no. 25, 1975.

12. G. Wall, "Bibliography on Exergy," more than 2000 references to exergy publications, available on diskett (Microsoft Excel) from the auther by sending USD 10 in cash. 
13. G. Wall, “Exergy - a Useful Concept,” Thesis, Chalmers Univ. Tech., Göteborg, Sweden, 1986.

14. G. Wall, E. Sciubba \& V. Naso, "Exergy use in the Italian society," ENERGY, vol. 19, pp. 1267-1274, 1994.

15. G. Wall, "The Exergy Conversion in the Society of Ghana," 8 p., presented at "The 1st International Conference on Energy and Community Development” Athens, 10-15 July, 1978.

16. B. Thorén, personal correspondence, 1993.

17. G. Wall, "Exergy Conversion in the Swedish Society," RESOURCES and ENERGY, vol. 9, pp. 55-73, 1987.

18. G. Wall, "Exergy Conversion in the Japanese Society,” ENERGY, vol. 15, no. 5, pp. 435444, 1990.

19. D. Goodstein, Nature, vol. 368, 14 April, p. 598, 1994.

20. P. Malaska, "Nature-Oriented Technology,” Turku School of Economics and Business Adm., Finland, 1990.

21. A. M. Squires, The Tender Ship - Governmental Management of Technological Change, Birkhäuser, 1986.

22. N. Wiener, The Human Use of Human Beings, Cybernetics and Society, Riverside Press, 1950.

23. N. Brunsson, The Organization of Hypocrisy, Chichester: John Wiley, 1989.

24. G. H. von Wright, personal correspondence, 1994.

25. G. Lindgren, personal correspondence, 1993.

26. G. H. Brundtland, Our Common Future, World Commission on Environment and Development, Oxford University Press, 1989.

27. United Nations, Report of the United Nations Conference on Environment and Development, Rio de Janeiro, 3-14 June, New York, 1992

28. E. Scheurmann, ed., Der Papalagi - Die Reden des Südsee-Häuptlings Tuiavii aus Tiavea, Felsenverlag, Buchenbach/Baden, 1920. 